\title{
Micron
}

January 2013, Volume 44, Pages 373-383

http://dx.doi.org/10.1016/j.micron.2012.09.002

(c) 2012 Elsevier Ltd. All rights reserved.

\section{In situ distribution and characterization of the organic content of the oyster shell Crassostrea gigas (Mollusca, Bivalvia)}

\author{
Yannicke Dauphin $^{\mathrm{a}, *}$, Alexander D. Ball ${ }^{\mathrm{b}}$, Hiram Castillo-Michel ${ }^{\mathrm{c}}$, Corinne Chevallard ${ }^{\mathrm{d}}$, \\ Jean-Pierre Cuif ${ }^{a}$, Bastien Farre ${ }^{a}$, Stéphane Pouvreau ${ }^{e}$, Murielle Saloméc
}

\author{
a UMR IDES 8148, bât. 504, Université Paris Sud, F-91405 Orsay cedex, France \\ ${ }^{b}$ Mineralogy, Natural History Museum, Cromwell Road, London SW7 5BD, UK \\ ${ }^{c}$ ID21, ESRF, 6 rue J. Horowitz, F-38043 Grenoble, France \\ d IRAMIS, LIONS, UMR SIS2M 3299, CEA, F-91191 Gif sur Yvette, France \\ e Physiologie des Invertébrés, IFREMER, Station d'Argenton, F-29840 Argenton en Landunvez, France \\ *: Corresponding author: Yannicke Dauphin, Tel.: +33 169156117 ; fax: +33 169156123 ; \\ email address : yannicke.dauphin@u-psud.fr
}

\begin{abstract}
:
Cultivation of commercial oysters is now facing the possible influence of global change in sea water composition, commonly referred to as "ocean acidification". In order to test the potential consequence of the predicted environmental changes, a cultivation experiment was carried out. The left and right valves of the oyster shell Crassostrea gigas differ in their structure; moreover, lenses of non compact layers are irregular. The shell layers of juvenile $C$. gigas are studied using a variety of highly spatially resolved techniques to establish their composition and structure. Our results confirm the presence of three different calcitic structural types. The role of the lenses of chalky layers is not yet deciplered. Despite a common mineralogy, the elemental composition of the layers differs. The sulphur aminoacids and sulphated polysaccharide contents of the intracrystalline and intercrystalline matrices differ, as well as those of the structural types. The possible different sensitivity of these structures to environmental changes is still unknown.
\end{abstract}

\section{Highlights}

Cultivation of commercial oysters is facing the influence of global change in sea water composition. - Oyster shell layers are calcitic, with different microstructures. These layers are irregular and imbricated so that only in situ analyses are possible. In situ microscopic analyses show that the irregular layers have different organic compositions.

Keywords: Biomineral ; Mollusc shell ; Infrared spectroscopy ; Laser confocal Microscope ; MicroXANES 


\section{Introduction}

In the recent past, several episodes of mass mortality have affected the cultivated species of oysters with considerable societal consequences (Paulet et al., 1988; Miossec et al., 2009). Production of the ancient original French oyster, Ostrea edulis (the flat oyster), is now limited to 2,000 metric tons/year, a very small proportion compared to 140,000 metric tons, the estimate of the French annual production of Crassostrea gigas. Oyster cultivation has also been based on Crassostrea angulata, which was accidentally introduced on French coasts around 1920-21, up to its decimation the 1969-70 due to a viral disease. Thus, $C$. gigas has been introduced into France as a commercial species of importance for aquaculture.

Salinity and temperature tolerances of $C$. gigas vary widely, depending on variety and on geographical location. According to Bougrier et al. (1995), temperature is the main factor that drives all the physiological processes, including filtering activity, metabolism, and respiration. Over the last decade $C$. gigas was itself exposed to a dramatic combination of extrinsic and intrinsic threats (Samain et al., 2007; Buisson et al., 2008).

In addition to these series of biologically induced crises, a new phenomenon is now causing additional stress to oyster populations: ocean acidification. Oceans play a fundamental role in the exchange of $\mathrm{CO}_{2}$ with the atmosphere. Once dissolved in sea water, carbon dioxide can be used by organisms, or remain free in water. $\mathrm{CO}_{2}$ reacts with water molecules and forms $\mathrm{H}_{2} \mathrm{CO}_{3}$. Thus, there is a decrease in sea water $\mathrm{pH}$, but also in $\mathrm{CO}_{3}{ }^{2-}$ which is used by marine organisms to build shells or skeletons. It has been predicted that ocean acidification will have a direct impact on both cultured and wild populations of $C$. gigas, whose calcification rates may decrease by $10 \%$ in 2100 (Gazeau et al., 2007). The early development of $C$. gigas is affected by sea water acidification. Only $5 \%$ of eggs incubated in $\mathrm{pH} 7.4$ sea water developed veliger larvae with a normal shape and shell (Kurihara et al., 2007). A decrease in seawater $\mathrm{pH}$ has a negative effect on shell growth, mechanical properties and thickness of the foliated laths of $C$. virginica (Beniash et al., 2010). Mortality also increases in juvenile oysters exposed to high $\mathrm{CO}_{2}$ levels (Dickinson et al., 2012). Reports from private hatcheries and biological stations have drawn attention to the reduced rate of successful metamorphosis in oyster populations and the possible influence of a failure in the initial post-larval step: fixation to the substrate. In contrast to blue mussels (Mytilus edulis), for instance, which are fixed to the substrate through a specific organ (the byssus), oysters are fixed directly to their substrate by the shell. The method by which this fixation occurs was described in early studies on oyster embryology and juvenile stages (Ryder, 1882, 1883; Huxley, 1883): "the left lobe of the mantle stretches beyond its valve and, applying itself on the surface of the stone or shell to which the valve is to adhere, secretes shelly matter which cement the valve to its support" (Huxley, 1883).

Note must be made that, in contrast to the rather symmetrical shell produced by the larval oyster, asymmetry occurs immediately in the early postmetamorphosis stage: it is always the same side of the mantle which is involved in the fixation process. This has a significant impact on the microstructure of the shell. In contrast to most bivalve molluscs, the shells of which exhibit similar microstructures on both valves (although they may have not identical sizes or shapes), the two valves of oyster shells do not show the same structural layers. Both left and right valves (which are entirely calcitic), comprise a foliated (internal) layer, but only the right valve (the upper one) has an outer thin prismatic calcitic layer. In addition to this peculiarity associated with the distinct roles of the valves in fixation, with the prismatic layer missing on the fixed valve), oysters exhibit an additional specificity in shell mineralization: they are the only known mollusc to produce a chalky layer, an irregular calcareous structure whose formation creates more or less hollow chambers within the foliated layers of the two valves. The origin and role of the chalky layers were investigated in Ostrea edulis "to elucidate the bio-chemical factors and general conditions controlling shell-deposition" (Orton and Amirthalingam, 1927). It was then believed that the deposition of the chalky layers, "begins in oysters about two years old" and "occur alternating with varying thicknesses of nacreous deposits". Despite their chalky aspects, these deposits are crystalline (Orton and Amirthalingam, 1927). Thus, in spite of a simple structural scheme, evolutionary processes have given oyster shells a strongly specialized position among other Pelecypods, as previously pointed out by Huxley (1883). It is now known that chalky structures are present in juvenile shells.

Biomineralization mechanisms were submitted to equivalent changes which were progressively revealed by improved analytical techniques. One of the first microstructural studies of the shell was performed using TEM sections of the right valve of Crassostrea virginica (Tsujii et al., 1958). Only two layers were described in this study: the outer prismatic and the inner one, called "nacre" (although both are calcitic). The mineralogy and arrangement of the inner "nacreous" layer of $C$. virginica were then described by Watabe et al. (1958). Again the images clearly show that this inner 
layer is a foliated layer. The foliated inner structure of O. gigas was studied by Wada (1963).

The chemical contents of the oyster shells (minor and trace elements) were reported by Carriker et al. (1980, 1982, 1996), Almeida et al. (1996), Andrus et al. 2000) among others. Carriker et al. (1996) have compared the chemical compositions of the prismatic and foliated layers of shells grown in natural and enriched waters. The right and left valves are similar, but depending on the element, the prismatic and foliated layers are not chemically identical. In the calcitic prismatic margin of $C$. virginica, twelve elements are more concentrated in the right valve (e.g., $\mathrm{Na}, \mathrm{S}, \mathrm{Mn}$, etc.) whereas $\mathrm{Mg}, \mathrm{Ca}$ and $\mathrm{Sr}$ are similar. From a biochemical view point, the presence of organic sulphated sugars was shown, but shell layers were not separated (Simkiss, 1965). Differences in the organic content between the outer and inner layers of Ostrea edulis were first noticed by Beedham (1958): the outer layer contains traces of sulphur, whilst there are no detectable traces in the inner layer.

In such variable and complex shells (different layers in right and left valves, chalky layers within, external or internal relative to the foliated layer) separation of the distinct shell components is very difficult, making a reliable investigation of their respective chemical and biochemical compounds very difficult by conventional methods. Physical in situ characterizations of biochemical compounds have been shown to be very efficient methods in some previous studies dealing with mollusc shell composition. Synchrotron based XANES mapping, for instance, has demonstrated that sulphur is mainly associated with sulphated sugars, S-amino acids being scarce (Dauphin 2003; Dauphin et al., 2003a, b, 2005). The focus of the current investigation is to determine the chemical speciation and distribution of sulphur in the layers of juvenile shells of Crassostrea.

\section{Material and methods}

\subsection{Material}

Crassostrea gigas (Thunberg, 1793) (Bivalvia, Pteriomorphia, Ostreoida) is a marine epifaunal, suspension - filter feeder that cements itself to hard substrata and feeds on phytoplankton and protists. Its shell is extremely variable in shape dependent on the substrate. Studied specimens were collected as spat from natural recruitment in the Bay of Brest (North Brittany, France) in August 2008. At the age of 6 months, they were transferred into oyster bags at a density of 300 oysters per bag for culture. One month before the experiment, they were transferred to the Ifremer Shellfish Laboratory located at Argenton (North
Brittany, France), and maintained in standard rearing conditions: continuous running and oxygenated sea water at constant temperature $\left(15^{\circ} \mathrm{C}\right)$ and phytoplankton ad libitum (a mixture of two algae species, Chaetoceros calcitrans and Isochrysis aff. galbana). Studied specimens were 14-months old (ca. 5-6 cm in shell length).

\subsection{Scanning electron microscope (SEM)}

Inner surfaces, fractured and polished sections (cut perpendicular to the surface of the shells) were prepared. Polished sections and some fractures were etched with various acids, enzymes or bacteria (Frérotte et al., 1983) to reveal microstructural features. The detailed procedures of the sample preparations are given in the figure legends. Scanning electron microscope (SEM) observations were conducted using a Philips 505 and a Philips XL30 instrument housed at the UMR IDES 8148, Université Paris Sud.

\subsection{Fluorescence microscopy}

A first set of observations was conducted at the LIONS laboratory (CEA Saclay, DSM/IRAMIS/SIS2M) on an Olympus FV1000 confocal microscope. All the samples examined had been previously sectioned and polished to a smooth surface. An oil-immersion objective was used in order to achieve the best achievable spatial resolution $(\sim 200 \mathrm{~nm}$ horizontal resolution). Two different excitation wavelengths were used $488 \mathrm{~nm}$ (Argon) and $543 \mathrm{~nm}$ (He-Ne). Confocal microscopy was also carried out at the Natural History Museum (NHM), London using a LEICA TCS-NT SP1. Lower magnification images were obtained using noncontact objective lenses. Higher resolution images used oil-immersion objectives, and coverslips temporarily applied to the samples using immersion oil. A $488 \mathrm{~nm}$ argon laser was chosen for excitation of fluorescence with a detector window set for FITC-type emission (515-545 nm). A $633 \mathrm{~nm}$ He-Ne laser was used with a detector window set at $625-641 \mathrm{~nm}$ to detect reflection from the crystalline shell structure at the same spatial position.

\subsection{Acridine orange staining}

Polished surfaces were stained with a solution of Acridine orange $\left(20 \mathrm{mg}\right.$ acridine, $90 \mathrm{~mL} \mathrm{H}_{2} \mathrm{O}$ and 10 $\mathrm{mL}$ methanol) for $24 \mathrm{~h}$ at room temperature, rinsed in Milli-Q water and air dried. Epifluorescence of stained surfaces was observed under ultraviolet light using a Zeiss Standard microscope equipped with Neofluor objectives, a Zeiss mercury lamp, excitation filter (365 $\mathrm{nm})$, and transmission cut-off filter (400 nm). Acridine 
orange is used to stain for sulphated sugars (Dauphin, 2003; Marlowe and Dillman, 1995).

\subsection{Fourier Transform Infrared Microscopy (FTIR)}

The synchrotron infrared microscopy was performed on the FTIR end-station of the ID21 beam line at the European Synchrotron Radiation Facility (ESRF). This beam line is equipped with a Continuum IR microscope (Thermo Nicolet) coupled to a Nexus FTIR bench (Thermo Nicolet). The microscope can be operated in confocal or reflection mode, where the focusing Schwarzschild objective and the collection Schwarzschild objective have a magnification of $32 \mathrm{x}$ $(\mathrm{NA}=0.65)$. Due to its reduced source size and high collimation properties, a synchrotron IR source is more efficiently coupled to the low acceptance of the confocal microscope, while its higher spectral luminescence (brightness) allows signal-to-noise ratios to be kept at diffraction-limited resolutions. The microscope is equipped with a computer-controlled x/y stage allowing acquisition of profiles or maps of the sample. Maps were scanned with steps of $4 \mu \mathrm{m}$ in both directions, with an aperture size of $5 \times 5 \mu \mathrm{m}^{2}$. Spectra were collected in reflection mode, with a resolution of $8 \mathrm{~cm}^{-1}$. For each spectrum, 100 scans were accumulated in the wavenumber range 4000 to $700 \mathrm{~cm}^{-1}$. Polished and cleaned surfaces were prepared as for the first step of SEM observations, without etching. The final format of the data was recorded as absorbance values.

\subsection{Micro-XANES - X-ray Absorption Near Edge Structure spectroscopy}

This work was carried out at the ID21 beamline of the ESRF. The ID21 Scanning X-ray Microscope uses Fresnel zone plates as focussing optics to generate a submicron X-ray probe. An energy-dispersive highpurity Ge detector (Princeton, Gamma-Tech) mounted in the horizontal plane perpendicular to the beam collects the fluorescence emission photons. This geometry minimizes the contribution of elastic scattering. An energy range between 2 and $7 \mathrm{keV}$ is available, which gives access to the K-edge of sulphur at $2472 \mathrm{eV}$. The XANES energy scan around the sulphur K-edge is achieved using a fixed-exit doublecrystal $\mathrm{Si}(111)$ monochromator located upstream from the microscope, which offers the necessary energy resolution. This experiment required the X-ray microscope to be operated under vacuum to avoid the strong absorption of the sulphur emission lines by air. Although the primary beam energy was set around that of the S K-edge energy region, elements with absorption edges at lower energies were also subject to excitation and emission of fluorescence photons, and could therefore be determined. Micro-fluorescence element maps of $\mathrm{Mg}$ and $\mathrm{P}$ were obtained simultaneously with the $\mathrm{S}$ maps, so that possible correlations between element repartition will be visible. Polished samples were etched with $1 \% \mathrm{v} / \mathrm{v}$ acetic acid for 5 seconds. Etching of the sample after polishing helped to eliminate potential surface contamination and remains of the diamond pastes and oil.

\section{Results}

Both right (flat) and left (cupped) valves of Crassostrea are irregular (Fig. 1a) and show lateral expansions (Fig. 1b, c). There is no pallial line, nor teeth, but the scar of the adductor muscle, which is used by the animal to close the shell, is visible (Fig. 1b, c). A section throughout the thickness of the shell shows natural cavities (Fig. 1d).

\subsection{Micro- and nanostructures}

The right valve has three layers. The thin outer layer (Fig. 2a) is composed of prismatic units surrounded by thick organic envelopes (Fig. 2b). The prisms are large and short, and their outer surface shows concentric growth lines in the juvenile organism (Fig. 2c). Growth lines within the prisms and organic interprismatic envelopes are visible (Fig. 2d). Such growth lines on the surface of the organic envelopes are preserved even after a mild decalcification (Fig. 2e). The inner structure of a prism is complex, and shows lamellar subunits the thickness of which is about 0.25 ì $\mathrm{m}$ (Fig. 2f, g). The inner lamina seems to be enveloped in an organic membrane, mimicking the nacreous structure. The outer scales of the right valves are built by the outer prismatic layer. Lenses of "chalk" are more or less abundant, and arranged in a layered structure (Fig. 2a, h). The chalky layer is known only in oysters, and the calcitic crystals have an unusual shape. They are geometric and superficially resemble desert or sand roses (Fig. 2i). Foliated layers are inserted in the chalky zones (Fig. 3a, b). The triangular ends of the layers of the laths are sharp (Fig. 3c, d). An enzymatic proteolysis of the laths shows that the triangular pattern is preserved throughout the growth of the unit (Fig. 3e). The boundary between the foliated and the prismatic layer is visible because the interprismatic organic envelopes do not grow in the foliated layer (Fig. 3f).

\subsection{Bulk composition}

The three layers of the shell are displayed on the polished surface of a right valve of an adult specimen (Fig. 4a). When subjected to a $633 \mathrm{~nm}$ illumination, growth layers and organic envelopes are visible within 

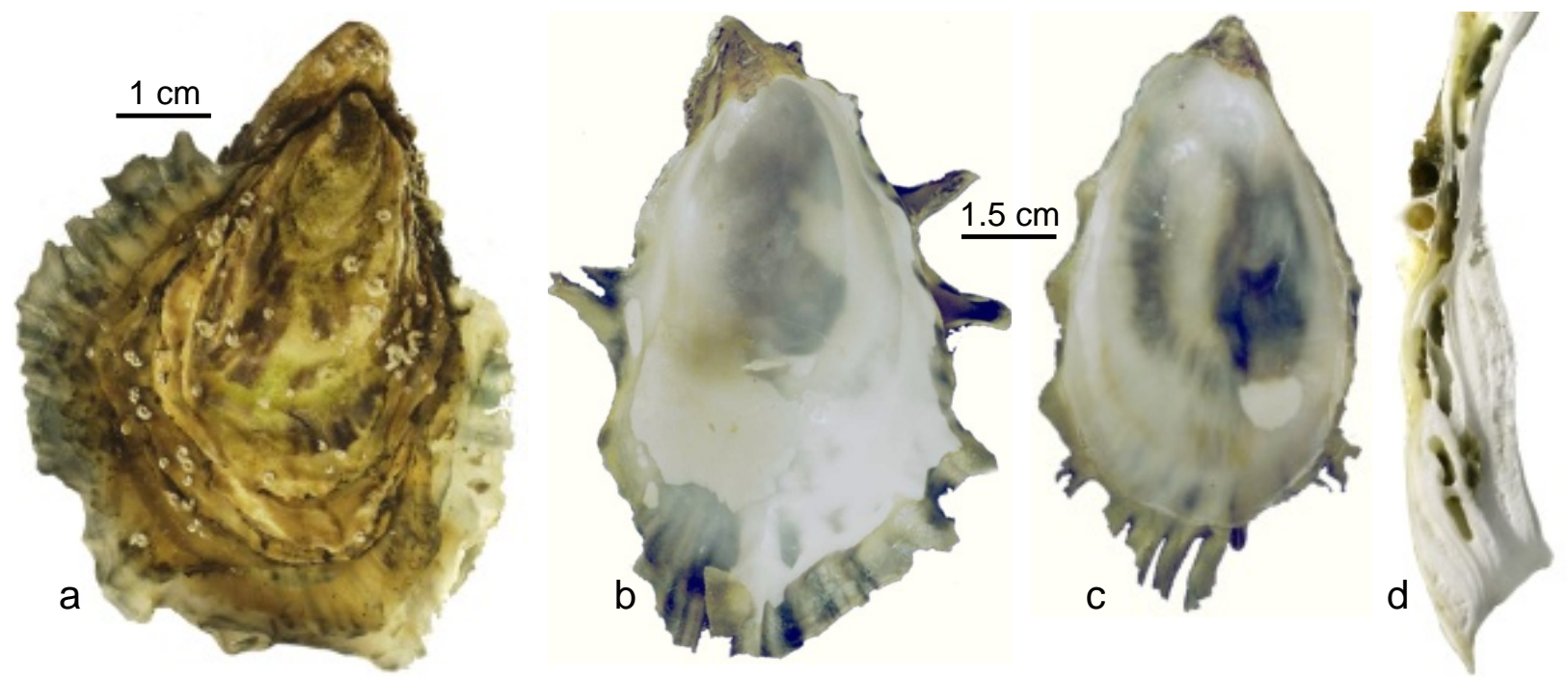

Fig. 1. Morphology of Crassostrea gigas. a- Outer view of the shell. b, c- Inner view of the left valve showing the muscle scar. d- Section throughout the thickness of the shell showing the natural cavities.
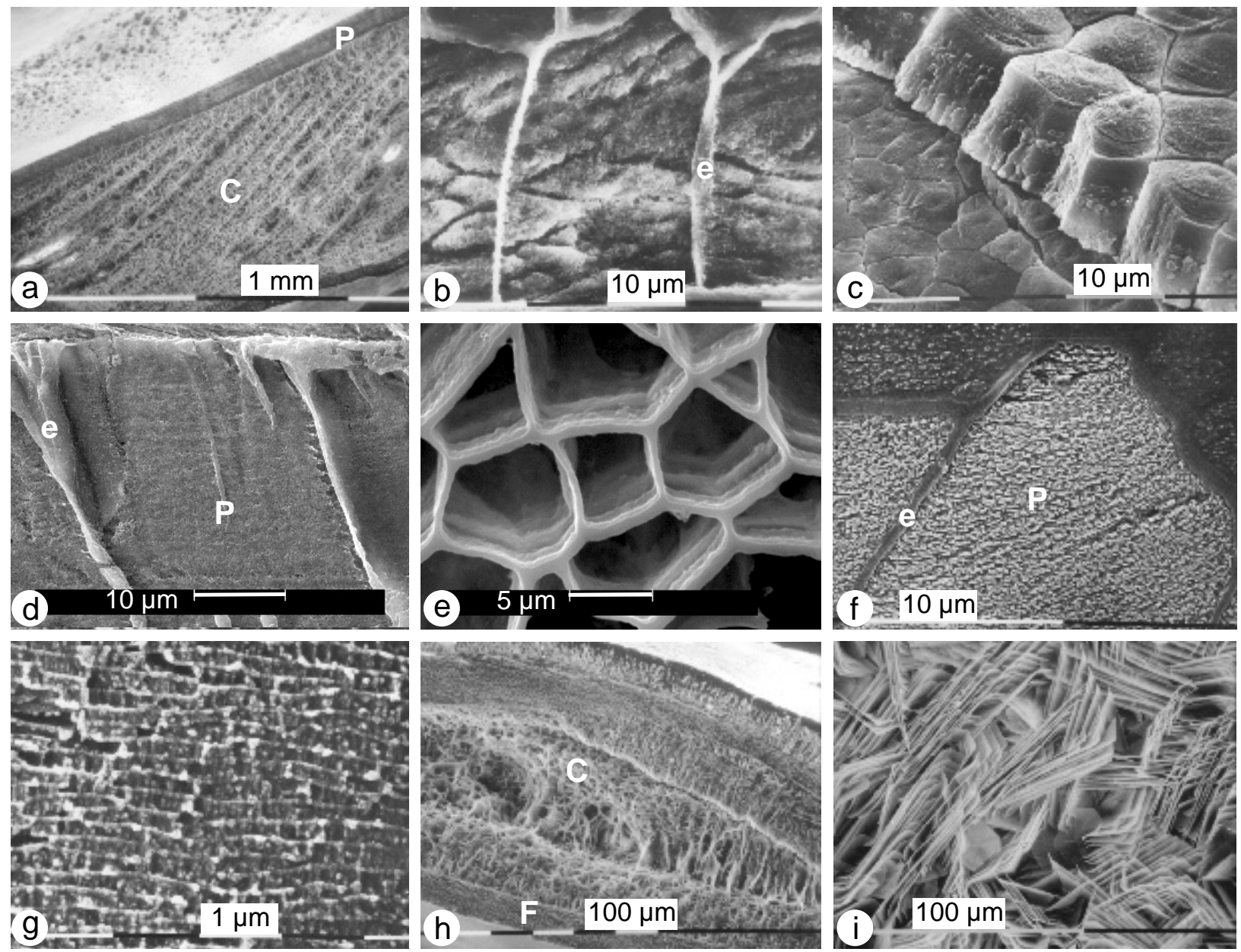

Fig. 2. Microstructures of the shell. a- Polished and etched section of the left valve showing the thin outer prismatic layer $(\mathrm{P})$ and the layered chalky region $(\mathrm{C})$. Etched with 5\% Formic acid for 10 sec. b- Polished and etched surface showing the thick organic envelopes of the prismatic units. $1 \%$ Formic acid for 10 sec. c- Outer view of a juvenile shell (right valve) with the prismatic layer; concentric growth lines are visible on the outer surface of the prisms after the removal of the periostracum. Etched with sodium hypochlorite for $15 \mathrm{~min}$. d- Polished section through the prismatic layer, showing the thick organic envelope and the inner growth lines. Fixed and etched with $0.1 \%$ Formic acid + glutaraldehyde for $45 \mathrm{sec}$. e- Prismatic layer: only the interprismatic organic envelopes are preserved, with visible growth lines. Etched with sodium hypochlorite for 18 hours. f- Polished oblique section of the right valve, showing the inner structure of a prismatic unit. Fixed and etched with the Mutvei's solution (acetic acid + glutaraldehyde) for $30 \mathrm{sec}, \mathrm{pH}$ 3. g- Detail of the same layer. h- Unetched fracture of the left valve, showing chalky deposits. i- Unetched inner surface of the right valve showing a chalky deposit. 

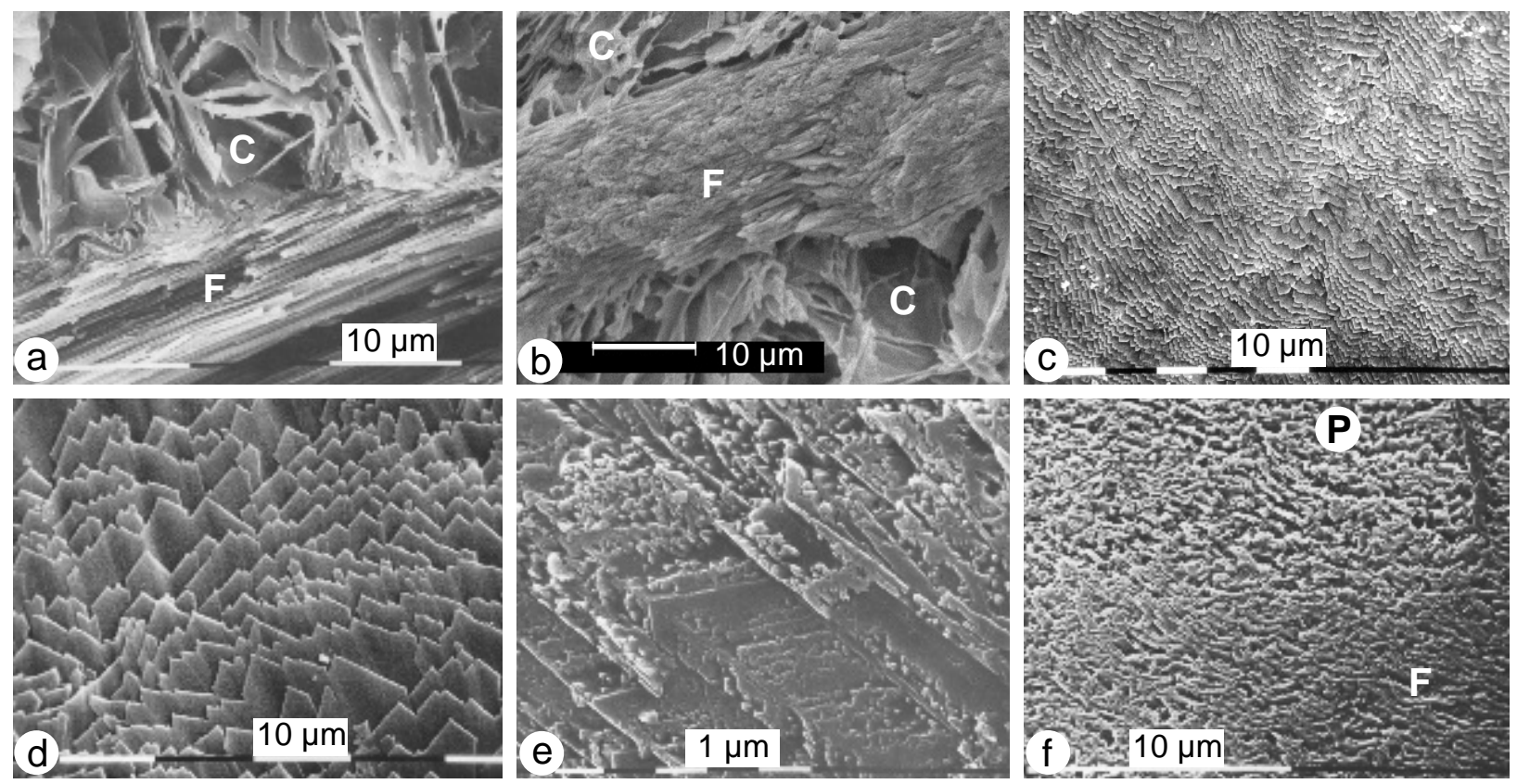

Fig. 3. Structural details of the layers. a- Fractured and untreated valve showing the chalky layer $(\mathrm{C})$ and the foliated layer $(F)$. b- Polished and etched surface showing the foliated layer (F) between two chalky lens in the hinge region of the right valve of a juvenile sample. Etched with acetic acid (0.1\%) and glutaraldehyde $2 \%$ for 10 sec. cUnetched inner surface of the upper (right) valve showing the layer structure of the foliated layer. d- Detail of the ends of the laths of the foliated layer. Unetched sample. e- Fracture of the foliated layer after a bacterial etching for 3 months, showing the triangular growth lines within a lath. Right valve. f- Polished and etched surface showing the transition between the prismatic layer $(\mathrm{P})$ and the foliated layer $(\mathrm{F})$. Both layers shown thin growth layers. Etched with Mutvei's solution for $2 \mathrm{~min}$.
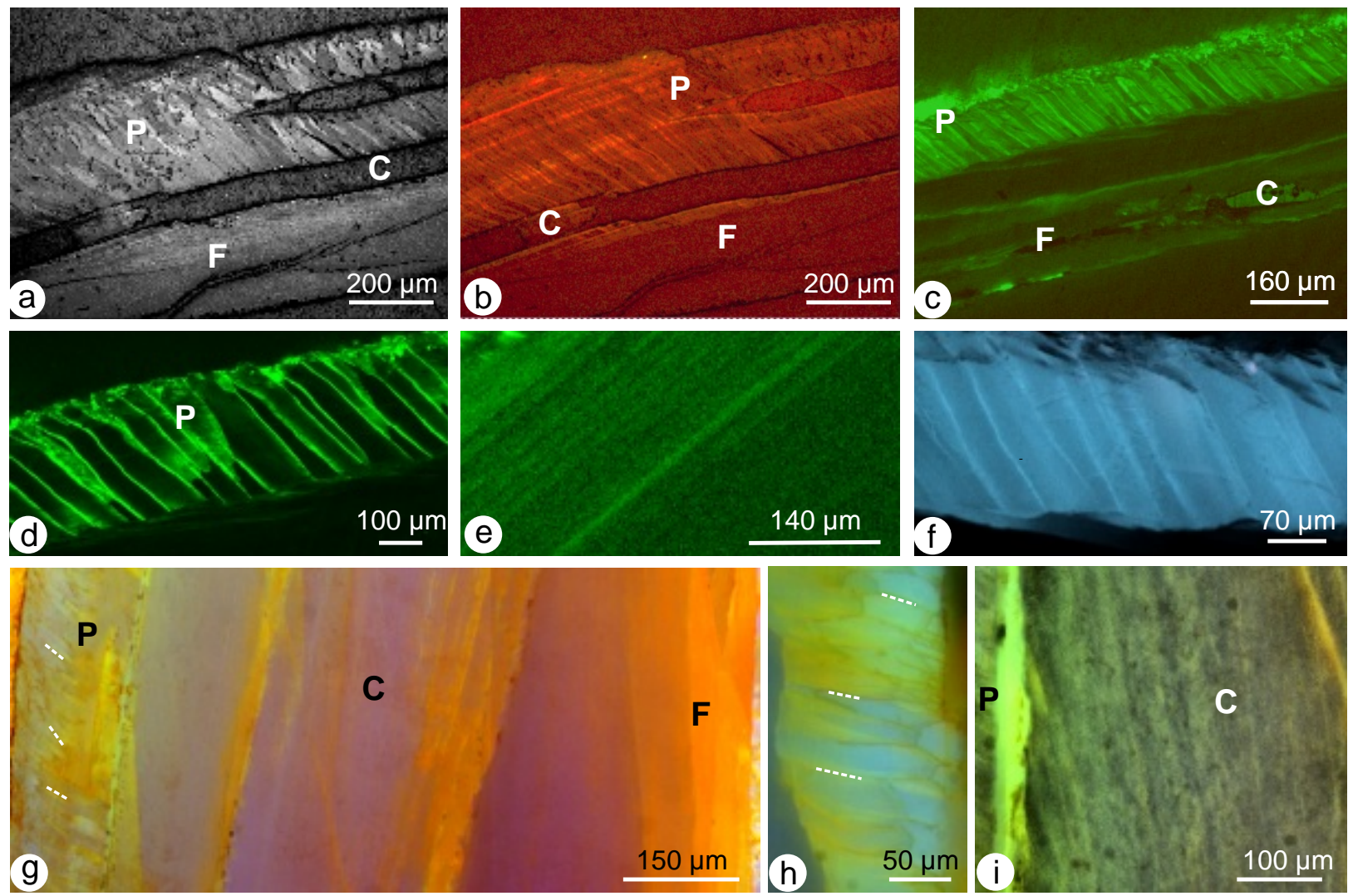

Fig. 4. Confocal microscope images. a- Topographic image of a vertical section of the left valve, showing the three main structures. b- Vertical section showing the three structures of the left valve of a juvenile shell, with distinct prisms (P) and growth layers. The structure of the chalky (C) and foliated (F) layers are less distinct. Excitation wavelength $633 \mathrm{~nm}$. c- Vertical section showing the three structures of the left valve of a juvenile shell. Excitation wavelength $488 \mathrm{~nm}$, emission wavelength $526 \mathrm{~nm}$. d- Detail of the same section showing the organic envelopes of the calcitic prisms. Excitation wavelength $488 \mathrm{~nm}$, emission wavelength $526 \mathrm{~nm}$. e- Detail of the foliated layer, showing major growth bands. Excitation wavelength $488 \mathrm{~nm}$, emission wavelength $526 \mathrm{~nm}$. f- Fluorescence image of the calcitic prismatic layer of the left valve of a juvenile shell. g-i: Epifluorescence images of Acridine orange staining of the sulphated sugars, showing the differential response of the layers $(\mathrm{g})$, and within a layer of the organic envelopes (h) and the irregular chalky layer (i). White dotted lines: interprismatic organic membranes. 
the prismatic layer (Fig. 4b). Structural details are not visible in the chalky and foliated layers (Fig. 4b). Illumination with a $488 \mathrm{~nm}$ laser shows a similar pattern in the right valve of a juvenile sample (Fig. 4c, d). Larger magnifications highlight the layered structure of the foliated layer in a juvenile sample (Fig. 4e). An epifluorescence image shows the organic envelopes of the prisms, but growth layers are not visible (Fig. 4f). Acridine orange stained sections show that the colour is not uniform, due to the difference in sulphated polysaccharides in the layers (Fig. 4g-i). The organic envelopes of the prisms are clearly visible (Fig. $4 \mathrm{~g}, \mathrm{~h}$ ), as well as the irregular structure of the chalky layer (Fig. 4i).

\subsection{FT-IR maps}

The right valve of a juvenile specimen was examined (Fig. 5). Low magnification images of the polished surface show that the outer prismatic layer is irregular and thin, the chalky layer is sparse, whilst the main part of the valve is the foliated structure (Fig. 5ad). The presence and the orientation of the prisms in the mapped zone (Fig. 5d, e) were confirmed using fluorescence microscopy (Fig. 5c). All the layers are calcitic, but the porous irregular chalky layer is clearly visible (Fig. 5f, g: C) at the $v 2\left(845 \mathrm{~cm}^{-1}\right)$ and $v 1(1010$ $\mathrm{cm}^{-1}$ ) bands. Because the chalky layer is porous, the resin used for embedding the samples penetrates it and cannot be excluded from the analyses. The $v 1$ and $v 2$ band maps differ, because these bands are also present in some organic components ( $\mathrm{C}-\mathrm{H}$ bond). These components are also visible in the resin utilised, but in different ratios. The $1030 \mathrm{~cm}^{-1}$ band is usually assigned to sugars and is present in chitin; again the chalky layer is different (Fig. 5h) when compared to the foliated and prismatic layers, but it is also clearly different when compared to the resin. The amide II map $\left(1573 \mathrm{~cm}^{-1}\right.$, Fig. 5i) is similar to that of the $1012 \mathrm{~cm}^{-1}$, in which the chalky layer and resin seem similar. This band is usually assigned to $\mathrm{COO}^{-}$in aspartic acid, but the second band $\left(1716 \mathrm{~cm}^{-1}\right)$ is not differentiated in the oyster map. Two maps using two amide I bands do not show the same pattern (Fig. 5j, k). Nevertheless, in both maps the thin prismatic layer seems to differ from the main foliated layer. The amide I at $1656 \mathrm{~cm}^{-1}$ band is indicative of $\alpha$ helix secondary structure, whereas $1636 \mathrm{~cm}^{-1}$ is indicative of $\beta$ sheet conformations.

\subsection{XANES}

Because of the different structure of the left and right valves, and the irregular distribution of the foliated - chalky layers, several specimens have been mapped. The first sample is a left valve with a chalky lens within the foliated layer (Fig. 6). The outer prismatic layer is absent in left valves. The inner and outer surfaces of the valve are rich in organic sulphate; the outer part is the remains of the organic periostracum, whereas the inner one is probably the remains of the pallial tissue (Fig. 6a). Growth lines are visible in the foliated layer; moreover the foliated layer has a variable sulphate content. The irregular structure of the chalky lens is visible. The variable content of the foliated layer is also visible in the map of sulphur rich amino acids (Fig. 6b). The organic inner and outer layers are less distinct. The chalky layer is visible in $\mathrm{Mg}$ and $\mathrm{P}$ maps (Fig. 6c, d), as well as the inner and outer organic remains. The two inner sublayers of the foliated structure are visible in the $\mathrm{P}$ map, but the separation is faint in the $\mathrm{Mg}$ map. Detailed maps of the chalky layer clearly show the irregular structures (Fig. 6e-h). Thin growth lines in the foliated structure and chalky lens are visible in sulphate and P maps of the left valve of another oyster (Fig. 7a, b). They are faint in the Mg map (Fig. 7c).

The outer prismatic layer was observed using the right valve of a juvenile sample (Fig. 8). From the outer surface to the inner part, growth zonations are visible, and the sulphate content decreases (Fig. 8a). The organic envelopes of the prismatic units are low in sulphate, but rich in sulphur amino acids (Fig. 8b). Growth zonations are faint (Fig. 8b). Organic prismatic envelopes are rich on $\mathrm{P}$, and a growth zonation is visible (Fig. 8d). Mg map features are similar to those of sulphate maps, although less distinct (Fig. 8e).

\section{Discussion}

The long recognised structural differences between the right and left valves in adult shells also exist in juvenile samples, as well as the presence of the chalky zones. Such structural differences are reflected in their different respective gross compositions, organic and mineral. Moreover, within a given valve, biochemical components also differ between layers, despite being entirely calcite in composition. In vitro experiments have demonstrated the role of polysaccharides (Albeck et al., 1996) and sulphates (Kitano et al., 1975) in biomineralization. However, the distribution and speciation of $\mathrm{S}$ in mollusc shells composed of several calcitic layers, the structures of which differ, has not yet been examined. Electron microprobe analyses have shown that $\mathrm{Mg}$ and $\mathrm{S}$ are more abundant in the prismatic layer (Frérotte, 1987), whereas $\mathrm{Na}$ and $\mathrm{P}$ are more abundant in the foliated layer (Fig. 9). Because of the non compact structure of the chalky layer, no detailed quantitative data are available. Organic envelopes of the prisms and growth lines in both prisms and foliated layers are revealed in SEM and confocal microscopy 

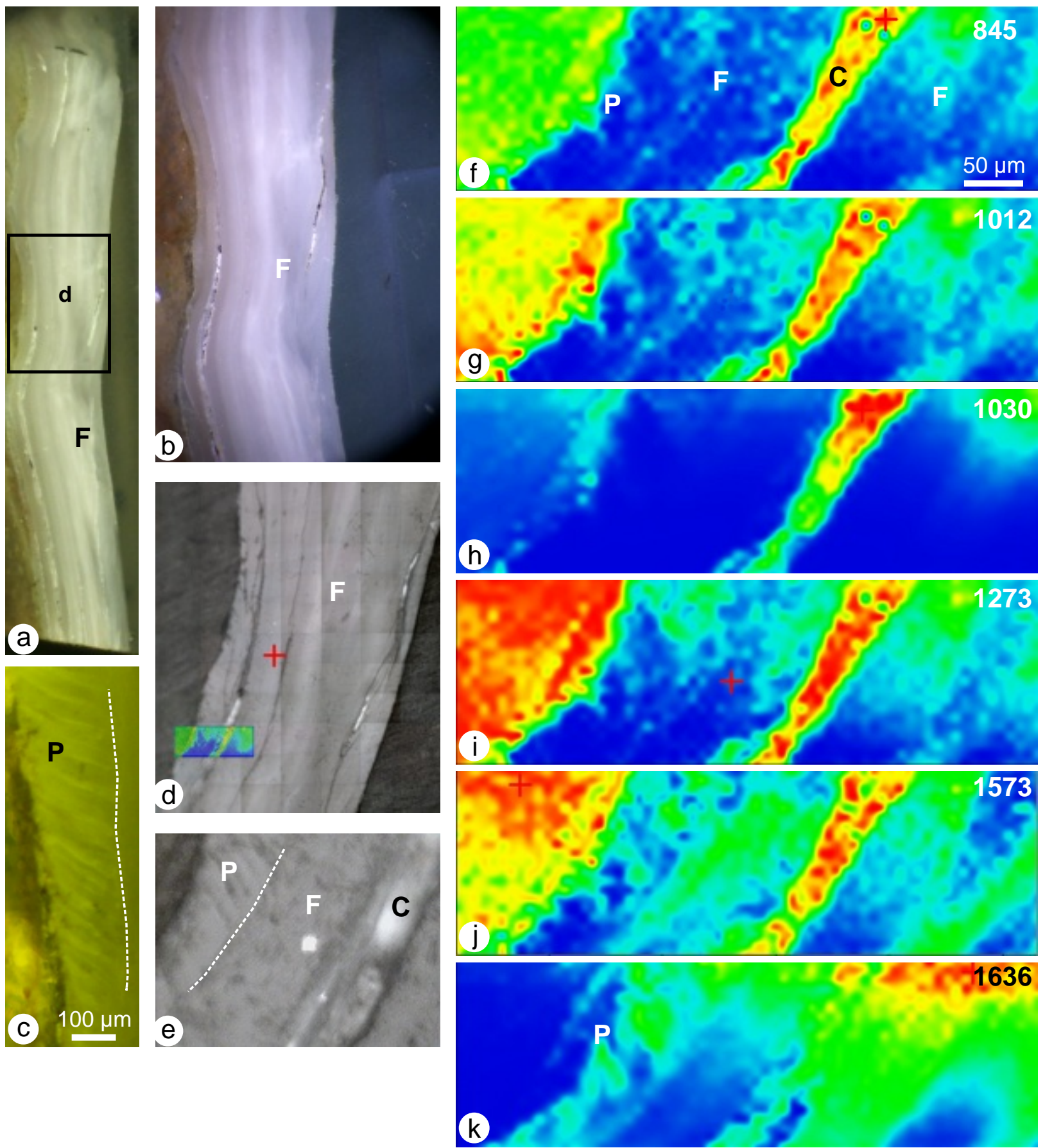

Fig. 5. FTIR maps of the right valve of a juvenile shell. a- Polished surface. At low magnification, the outer thin prismatic layer is not clearly visible. Only the layered arrangement of the foliated layer $(F)$ is displayed. b- Detail of the same, showing the porous chalky layer. c- Fluorescence image of the outer prismatic layer. d-e: Detailed images showing the location of the FTIR maps. f-k: Fourier transform infrared maps in the outer prismatic layer, a part of the chalky layer and the outer part of the thick foliated layer. $f: n 2$ band of calcite. $g: n 1$ band of calcite. h: band in sugars in chitin. I: amide II band. j: amide I band. k: amide I band. White dotted lines: prismatic - foliated layers boundary. 

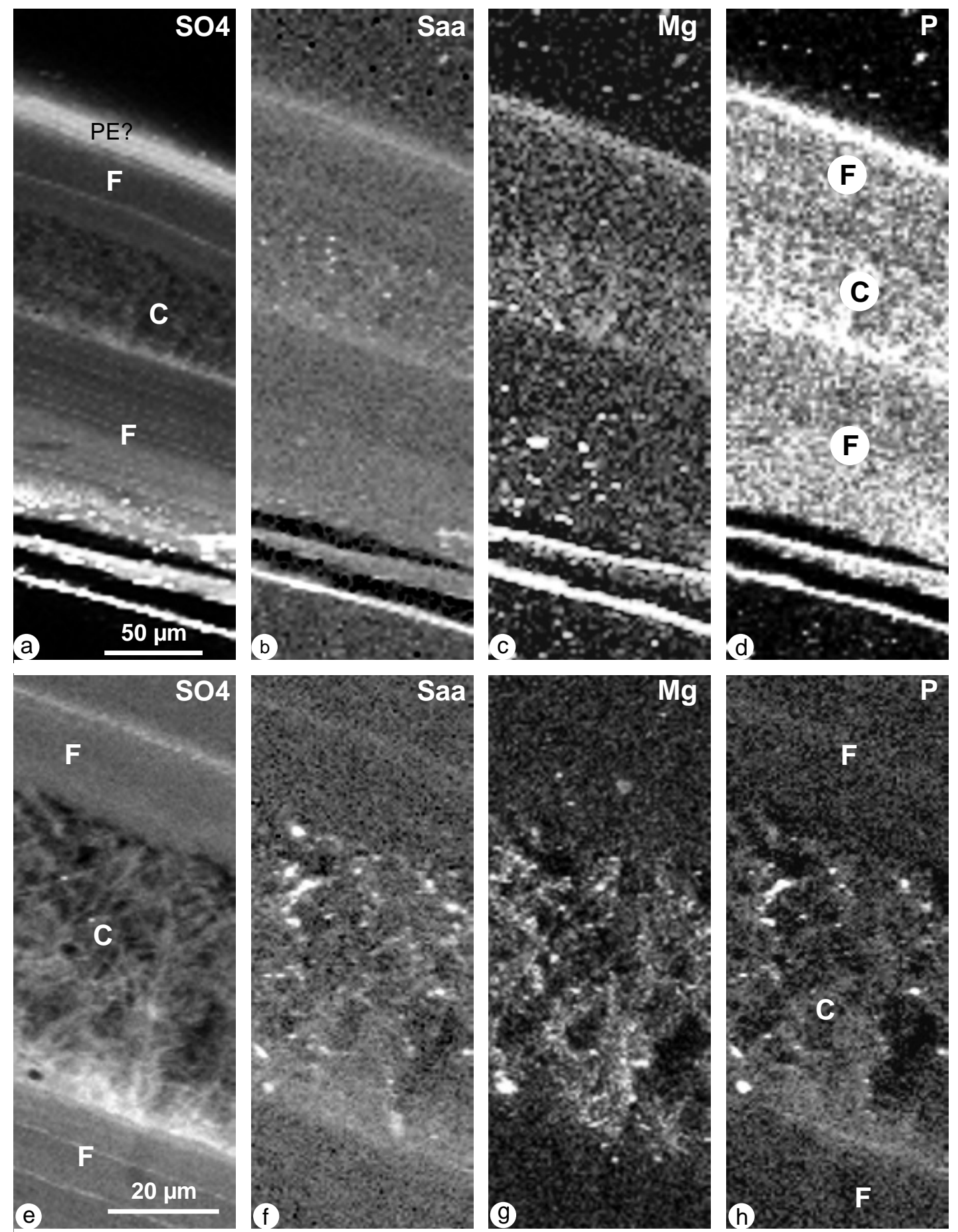

Fig. 6. XANES images of the left valve of a juvenile shell. a-d: Several sublayers of foliated structures are intersected by the chalky layer. Growth lines are visible in organic sulphate (a) and sulphur aminoacid (b) maps. e-f: Detail of the structure of the porous chalky layer between two foliated zones. PE?: periostracum (?); F: foliated layer; C: porous chalky layer; P: prismatic layer. 

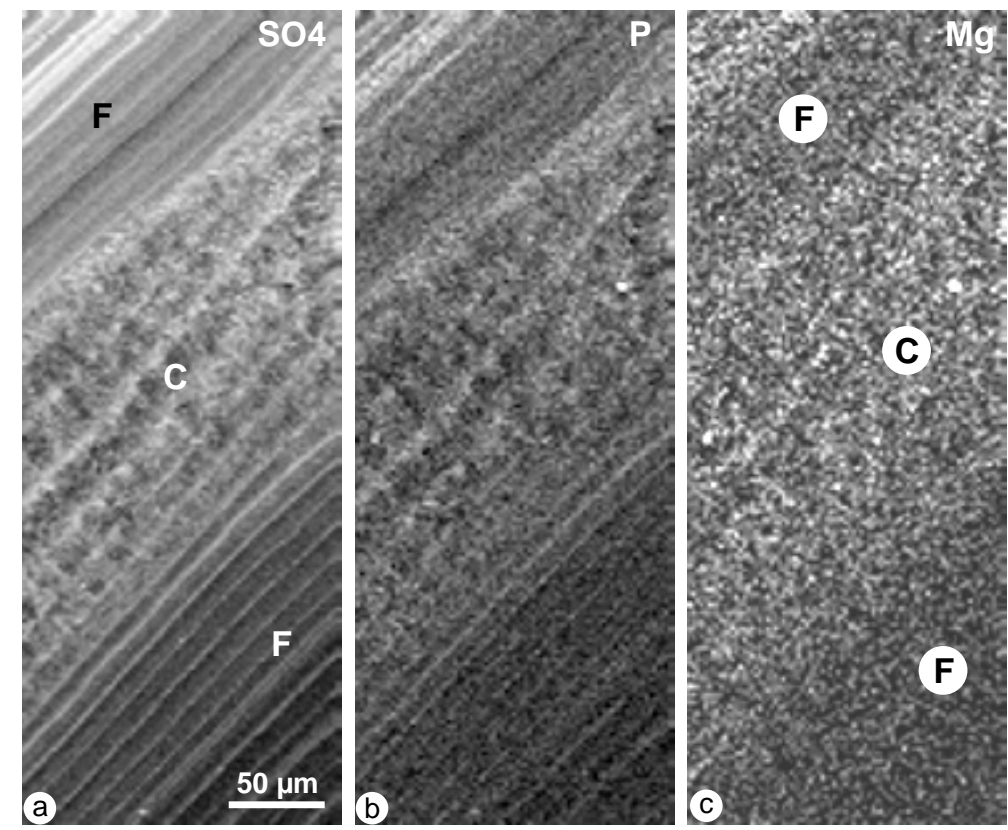

Fig. 7. XANES images of the left valve of a juvenile shell. Foliated and chalky layers show more or less regular growth lines in organic sulphate (a), phosphorus (b) and magnesium (c) maps.
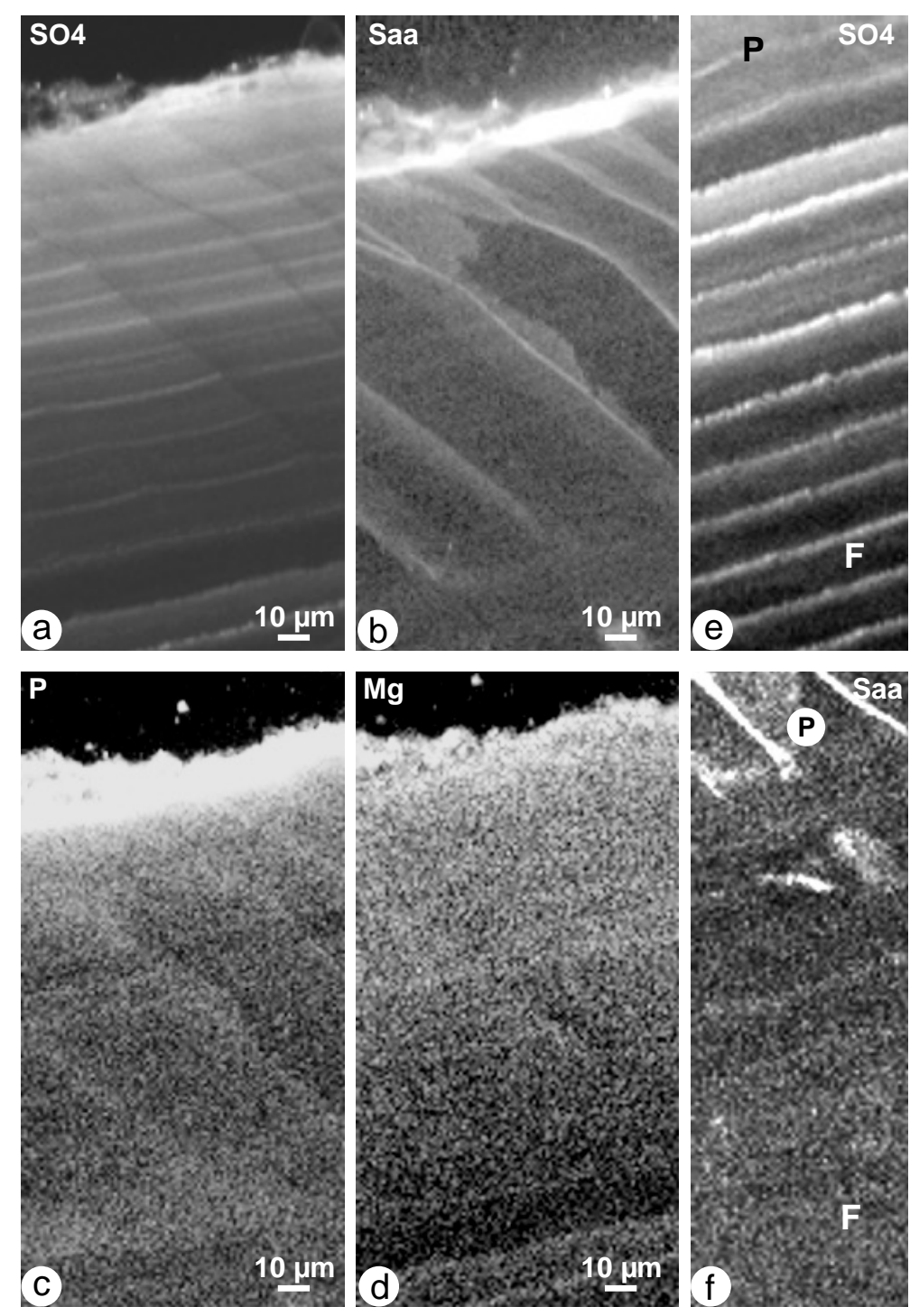

Fig. 8. XANES images of the right valve of a juvenile shell showing the variable aspect of the prismatic layer. Organic envelopes are visible for sulphates (a), S amino acids (b), but also in P (d). They are faint in $\mathrm{Mg}$ (e). Growth bands are mainly visible on the sulphate map (a). Growth bands are clearly visible in the foliated layer for sulphates (c), whereas they are faint in S aminoacids (f). PE(?): periostracum. XANES images of the left valve of a juvenile shell. Foliated and chalky layers show more or less regular growth lines in organic sulphate (a), phosphorus (b) and magnesium (c) maps. 
images. Growth lines and organic envelopes are also visible in XANES maps, either for $S$ speciation or elemental maps. Organic sulphates are more abundant than $\mathrm{S}$ amino acids in the intracrystalline matrices, whereas $\mathrm{S}$ amino acids are more abundant in the organic envelopes of the prismatic layers. Major growth rhythms are also displayed by organic sulphate maps in the foliated layer. A similar pattern is shown by P maps. These structures are not well differentiated in FTIR maps. However, these maps show that the distribution of organic components is heterogeneous, as shown by amide components.

This study confirms the presence of organic sulphated polysaccharides previously observed by Beedham (1958). As for other calcitic prismatic layers of mollusc shells, organic sulphates are abundant in the intracrystalline organic matrices, so that thin growth lines can be observed in distribution maps (Dauphin et al., 2005; Guzman et al., 2007). Similarly, the organic envelopes surrounding the prisms are rich in $S$ aminoacids, as already observed in the prismatic layers of Pinna and Pinctada. Mollusc shells previously studied using XANES and/or FTIR maps are composed of calcite and aragonite. No data about shells composed of several calcitic layers are available. Nevertheless, differences have been detected in brachiopod shells (Cusack et al. 2008). The abundance of organic sulphate and sulphur amino acids differs in the inner and outer layers, both calcitic. Growth lines are visible in the thick secondary layer. It must be noted that despite their common mineralogy, $\mathrm{Mg}$ and $\mathrm{P}$ contents differ in the primary and secondary layer of $T$. retusa.

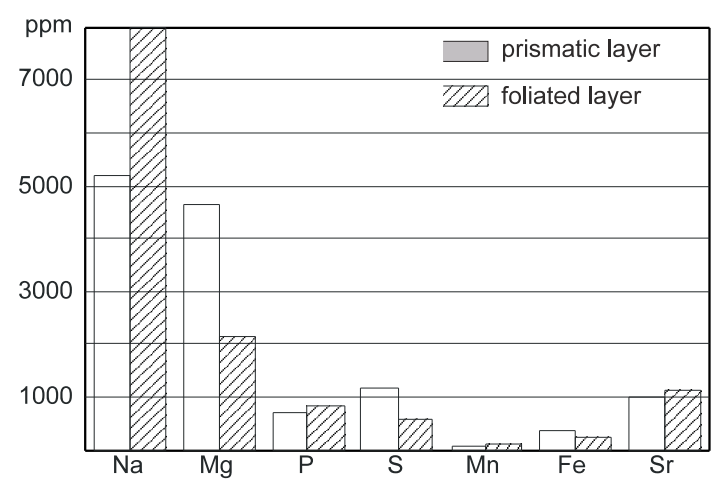

Fig. 9. Elemental chemical composition of the two compact layers of the shell.

\section{Conclusion}

Sulphur content and speciation differ according to the microstructure of the valve layers, a distinctive feature of Crassostrea shell microstructure. Noticeably, organic sulphate content of the microstructural units is always higher than that of S amino acids, independently of the microstructure of a given layer.
In oysters, it has been shown that temperature has a major role in physiology, but the impact of ocean $\mathrm{pH}$ and the consequences of the anthropogenic ocean acidification are not known. High $\mathrm{CO}_{2}$ concentrations induce an increase in juvenile mortality. Proteomic changes have also been observed in the mantle tissue of adult animals (Tomanek et al., 2011). The effects on larval stages are unknown, but acidification is expected to alter larval survival rates considerably. The observed proteomic modifications probably induced the changes in the shell structures. On the other hand, Crassostrea gigas seems more resistant to ocean acidification and higher temperatures than some other oysters (Parker et al., 2010). However, because of the irregular arrangement of the calcitic shells of Crassostrea, it is difficult, if not impossible to separate the different layers to study their mineral and organic components. Only in situ analyses are able to provide data on the distribution and composition of the mineral and organic components in normal or diseased organisms. The mechanical properties of the foliated and chalky layers differ (Lee et al., 2011), so that changes in the ratio of these two structures will influence the resistance of the shell, including during transportation of this food resource. Is the abundance of the chalky lenses dependant of the sea water acidification? Up to now, no data are available.

Owing to the practical difficulty in accurately separating the different layers of the oyster shell, particularly the intricate chalky and foliated layers, the probable differential sensitivity of the distinct shell layers to environmental changes has not been tested in this first approach. Clearly, predictive models will be much more reliable when a clear understanding of the sensitivity of the different layers can be taken into account. It is worth noting, however, that the noticeable accentuation of the morphological variations among juvenile shell valves, even if it does not significantly change the overall dimensions of the population, at least reveals that environmental conditions have a visible influence on growth regularity and shape regulation of the shells.

\section{Acknowledgements}

This work has been supported by grants through contracts ANR 11-BS10-005-02 (3D-PtyCCoBio project), CALMARO (ITN Marie Curie actions FP7), from the EC545 ESRF grant, and from the SYNTHESYS program through GB-TAF 1612.

\section{References}

Albeck, S., Weiner, S., Addadi L., 1996. 
Polysaccharides of intracrystalline glycoproteins modulate calcite crystal growth in vitro. Chemistry, A Eur. J. 2, 278-284.

Almeida, M.J., Moura, G., Machado, J., Coimbra, J., Vilarinho, L., Ribeiro, C., Soares-da-Silva, P., 1996. Amino acid and metal content of Crassostrea gigas shell infested by Polydora sp. in the prismatic layer insoluble matrix and blister membrane. Aquatic Liv. Res. 9, 179-186.

Andrus, C.F.T., Crowe, D.E., 2000. Geochemical analysis of Crassostrea virginica as a method to determine season of capture. J. Archaeol. Sci. 27, 33-42.

Beedham, G.E., 1958. Observations on the noncalcareous component of the shell of the Lamellibranchia. Quat. J. Microsc. Sci. 99, 341357.

Beniash, E., Ivanina, A., Lieb, N.S., Kurochkin, I., Sokolova, I.M., 2010. Elevated level of carbon dioxide affects metabolism and shell formation in oysters Crassostrea virginica (Gmelin). Mar. Ecol. Progr. Ser. 419, 95-108.

Bougrier, S., Geairon, P., Deslous-Paoli, J.M., Bacher, C., Jonquieres, G., 1995. Allometric relationships and effects of temperature on clearance and oxygen consumption rates of Crassostrea gigas (Thunberg). Aquaculture 134,143-154.

Buisson, S., Bouchart, V., Guerlet, E., Malas, J.P., Costil, K., 2008. Level of contamination and impact of pesticides in cupped oyster, Crassostrea gigas, reared in a shellfish production area in Normandy (France). J. Envir. Sci. Health B43, 655-664.

Carriker, M.R., Palmer, R.E., Sick, L.V., Johnson, C.C., 1980. Interaction of mineral elements in sea water and shell of oysters (Crassostrea virginica (Gmelin)) cultured in controlled and natural systems. J. Exp. Mar. Biol. Ecol. 46, 279-296.

Carriker, M.R., Swann, C.P., Ewart, J.W., 1982. An exploratory study with the proton microprobe of the ontogenetic distribution of 16 elements in the shell of living oysters (Crassostrea virginica). Mar. Biol. 69, 235-246.

Carriker, M.R., Swann, C.P., Ewart, J., Counts, C.L.III., 1996. Ontogenetic trends of elements ( $\mathrm{Na}$ to $\mathrm{Sr}$ ) in prismatic shell of living Crassostrea virginica (Gmelin) grown in three ecologically dissimilar habitats for 28 weeks: a proton probe study. J. Exp. Mar. Biol. Ecol. 201, 87-135.

Cusack, M., Dauphin, Y., Cuif, J.P., Salomé, M., Freer, A., Yin, H., 2008. Micro-XANES mapping of sulphur and its association with magnesium and phosphorus in the shell of the brachiopod, Terebratulina retusa. Chem. Geol. 253, 172-179.

Dauphin, Y., 2003. Soluble organic matrices of the calcitic prismatic shell layers of two pteriomorphid
Bivalves: Pinna nobilis and Pinctada margaritifera. J. Biol. Chem. 278, 15168-15177.

Dauphin, Y., Cuif, J.P., Doucet, J., Salomé, M., Susini, J., Williams, C.T., 2003a. In situ mapping of growth lines in the calcitic prismatic layers of mollusc shells using X-ray absorption near-edge structure (XANES) spectroscopy at the sulphur edge. Mar. Biol. 142, 299-304.

Dauphin, Y., Cuif, J.P., Doucet, J., Salomé, M., Susini, J., Williams, C.T., 2003b. In situ chemical speciation of sulfur in calcitic biominerals and the simple prism concept. J. Struct. Biol. 142, 272280.

Dauphin, Y., Cuif, J.P., Salomé, M., Susini, J., 2005. Speciation and distribution of sulfur in a mollusk shell as revealed by in situ maps using X-ray absorption near-edge structure (XANES) spectroscopy at the S K-edge. Amer. Miner. 90, 1748-1758.

Dickinson, G.H., Ivanina, A.V., Matoo, O.B., Pörtner, H.O., Lanning, G., Bock, C., Beniash, E., Sokolova, I.M., 2012. Interactive effects of salinity and elevated $\mathrm{CO}_{2}$ levels on juvenile eastern oysters, Crassostrea virginica. J. exp. Biol. 215, 29-43.

Frérotte, B., 1987. Etude de l'organisation et de la composition des biocristaux du test des lamellibranches. Thèse doct. 3è cycle, Univ. Paris Sud, 187 pp.

Frérotte, B., Raguideau, A., Cuif, J.P., 1983. Dégradation in vitro d'un test carbonaté d'Invertébré, Crassostrea gigas (Thunberg), par action de cultures bactériennes. Intérêt pour l'analyse ultrastructurale. C. R. Acad. Sci. Paris 297, sér. II, 383-388.

Gazeau, F., Quiblier, C., Jansen, J.M., Gattuso, J.P., Middelburg, J.J., Heip, C.H.R., 2007. Impact of elevated $\mathrm{CO}_{2}$ on shellfish calcification. Geophys. Res. Let. 34, L07603.

Guzman, N., Ball, A.D., Cuif, J.P., Dauphin, Y., Denis, A., Ortlieb, L., 2007. Subdaily growth patterns and organo-mineral nanostructure of the growth layers in the calcitic prisms of the shell of Concholepas concholepas Bruguière, 1789 (Gastropoda, Muricidae). Microsc. Microanal. 13, 397-403.

Huxley, T.H., 1883. Oysters and the oyster question. The Engl. Illustr. Mag. 1, 47-55 and 112-121.

Kitano, Y., Okumura, M., Idogaki, M., 1975. Incorporation of sodium, chloride and sulfate with calcium carbonate. Geochem. J. 9, 75-84.

Kurihara, H., Kato, S., Ishimatsu, A., 2007. Effects of increased seawater $\mathrm{pCO}_{2}$ on early development of the oyster Crassostrea gigas. Aquat. Biol. 1, 9198.

Lee, S.W., jang, Y.N., Ryu, K.W., Chae, S.C., Lee, Y.H., Jeon, C.W., 2011. Mechanical 
characteristics and morphological effect of complex crossed structure in biomaterials: fracture mechanics and microstructure of chalky layer in oyster shell. Micron 42, 60-70.

Marlowe, R.L., Dillman, R.M., 1995. Acridine orange staining of decapod crustacean cuticle. Invert. Biol. 114, 79-82.

Miossec, L., le deuff, R.M., Goulletquer, P., 2009. Alien species alert: Crassostrea gigas (Pacific oyster). ICES coop. res. Rep. 299, 42 pp.

Orton, J.H., Amirthalingam, G., 1927. Notes on shelldepositions in oysters. J. Mar. Biol. Assoc. UK 14, 935-953.

Parker, L.M., Ross, P.M., O'Connor, W.A., 2010. Comparinf the effect of elevated $\mathrm{pCO}_{2}$ and temperature on the fertilization and early development of two species of oysters. Mar. Biol. 157, 2435-2452.

Pauley, G.B., Van der Raay, B., Troutt, D., 1988. Species profiles: life histories and environmental requirements of coastal fishes and invertebrates (Pacific Northwest) - Pacific oyster. US Fish Wildl. Serv. Biol. Rep. 52 (11.85), 28 pp.

Ryder, J.A., 1883. On the mode of fixation of the fry of the oyster. Bull. US Fish Com. 2, 383-387.

Ryder, J.A., 1882. The metamorphosis and post larval stages of the development of the oyster. Rep. US Fish Com. 10, 779-791.
Samain, J.F., Degremont, L., Soletchnik, P., Haure, J., Bedier, E., Ropert, M., Moal, J., Huvet, A., Bacca, H., Van Wormhoudt, A., Delaporte, M., Costil, K., Pouvreau, S., Lambert, C., Boulo, V., Soudant, P., Nicolas, J.L., Le Roux, F., Renault, T., Gagnaire, B., Geret, F., Boutet, I., Burgeot, T., Boudry, P., 2007. Genetically based resistance to summer mortality in the pacific oyster (Crassostrea gigas) and its relationship with physiological, immunological characteristics and infection processes. Aquaculture 268, 227-243.

Simkiss, K., 1965. The organic matrix of the oyster shell. Comp. Biochem. Physiol. 16, 427-435.

Tomanek, L., Zuzow, M.J., Ivanina, A.V., Beniash, E., Sokolova, I.M., 2011. Proteomic responses to elevated $\mathrm{pCO}_{2}$ level in Eastern oysters Crassostrea virginica. J. Exp. Biol. 211, 1836-1844.

Tsujii, T., Sharp, D.G., Wilbur, K.M., 1958. Studies on shell formation. VII. The submicroscopic structure of the shell of the oyster Crassostrea virginica. J. Biophys. Biochem. Cytol. 4, 275-279.

Wada, K., 1963. Studies on the mineralization of the calcified tissue in Molluscs. VI. Crystal structure of the calcite grown on the inner surface of calcitostracum. J. Elect. Microsc. 12, 224-227.

Watabe, N., Sharp, D.G., Wilbur, K.M., 1958. Studies on shell formation. VIII. Electron microscopy of crystal growth of the nacreous layer of the oyster Crassostrea virginica. J. Biophys. Biochem. Cytol. 4, 281-284. 